\title{
Investigation of the effect of two new initiators of $p$-aminoazobenzene and diazoaminobenzene on the properties of polyaniline
}

\author{
S. Shabzendedar ${ }^{1}$, A. R. Modarresi-Alam ${ }^{1,2^{*}}$, M. Noroozifar ${ }^{3}$ \\ ${ }^{1}$ Organic and Polymer Research Laboratory, Department of Chemistry, Faculty of Science, University of Sistan and \\ Baluchestan, Zahedan, Iran \\ ${ }^{2}$ Renewable Energies Research Institute, University of Sistan and Baluchestan, Zahedan, Iran \\ ${ }^{3}$ Department of Physical and Environmental Sciences, University of Toronto, Scarborough 1265 Military Trail, \\ ON M1C 1A4 Toronto,, Canada
}

Received 14 April 2019; accepted in revised form 9 August 2019

\begin{abstract}
The flower-like dendrimer and the nanosheet synthesis of polyaniline in the template-free method (rapid mixing) have been done successfully using $p$-aminoazobenzene (PAAB) and diazoaminobenzene (DAAB) as two new initiators, respectively. In both syntheses, the ammonium peroxydisulfate is used as an oxidant. The effect of initiators on the morphology is demonstrated by scanning electron microscopy (SEM) and transmission electron microscopy (TEM) images, and the mechanism of nanostructure formation is presented. The polymers are characterized by Fourier transform infrared (FT-IR) and Ultraviolet-visible (UV-vis) spectroscopies and elemental analysis (CHNS). Cyclic voltammetry (CV), electrical conductivity, X-ray diffraction (XRD) and thermogravimetric analysis (TGA) are also presented. Both polymers are semi-crystalline in nature and had the same thermal behavior.
\end{abstract}

Keywords: nanomaterials, nanopolyaniline (dendrimer and nanosheet), p-aminoazobenzene, diazoaminobenzene

\section{Introduction}

Polyaniline is an important conductive polymer and has unique properties such as its easy synthesis, tunable conductivity switching between insulating and semiconducting materials, better environmental stability, reversible and easy acid doping/base dedoping behavior $[1,2]$. Scientists have recently paid more attention to one-dimensional (1D) nanostructures of polyaniline, such as nanowires, nanotubes, nanobelts, nanofibers, and nanorods [3-5] because of their important applications in energy storage devices $[6,7]$, superhydrophilic and superhydrophobic devices [8], actuators [9], chemical sensors [10,11], biosensors [12-14] and polymeric conducting molecular wires [15]. Several different chemical methods have been used to synthesize these nanostructures via template and template-free methods. By changing the reaction conditions, the morphology of the polymer changed to different shapes. For example, the use of different initiators can have an effective role in the obtained morphology. For example, Tran et al. [16] synthesized poly (o-anisidine) nanofibers using $p$-aminodiphenylamine (dimer) as an initiator, whereas the granuleshaped agglomerates obtained by analogous reaction with $p$-phenylenediamine (diamine). Zujovic et al. [17] obtained ultra-long polyaniline nanofibers using dimer or diamine as an initiator by a rapid mixing method. The nano and microsphere morphologies of poly $[( \pm)$-2-(sec-butyl) aniline] were obtained using the same initiators by Movahedifar et al. [18]. They

*Corresponding author, e-mail: modaresi@,chem.usb.ac.ir (C) BME-PT 
observed that using of the diamine initiator leads to the smallest polyaniline particles. In the present research, we used two new initiators [ $p$-aminoazobenzene (PAAB) and diazoaminobenzene (DAAB)] for the synthesis of new shapes of polyaniline. For the first time, the dendrimer morphology of the polyaniline has been obtained. Indeed, the fractal morphology of PANI-PMMA nanocomposites was reported by Menon and Mukherjee [19] and the branched polyaniline nanofibers by Sheng Du et al. [20]. Also, Wu et al. [21] obtained the fractal structure of sulfonated polyaniline colloidal aggregates but without apparent center and the sulfonated polyaniline colloidal particles appears as a sphere with more dendriform. However in this work, we synthesized the polyaniline dendrimer with a clear structure and apparent center for the first time by a very simple synthetic method and using DAAB as an initiator. Also, the polyaniline nanosheet was obtained using $\mathbf{P A A B}$ as an initiator. The nanosheet morphology of polyaniline has also been obtained by a number of other research groups [22-24] and the mechanism of nanosheet formation was reported [25-30] but in this work, the nanosheet morphology of the polyaniline was obtained by a new initiator.

\section{Experimental}

\subsection{Materials}

All chemicals were purchased from Fluka and Merck Chemical Co. (Germany). All chemicals were analytical grade and used as received, just the aniline was purified by distillation.

\subsection{Equipment}

Fourier transform infrared (FT-IR) spectra of the samples were recorded from $\mathrm{KBr}$ pellets on a PerkinElmer Spectrum Two spectrophotometer between 450 and $4000 \mathrm{~cm}^{-1}$ (USA). Ultraviolet-visible (UVvis) spectra were recorded on a Shimadzu UV-1800 spectrophotometer between 200 and $800 \mathrm{~nm}$ by dissolving the samples in $N$-methylpyrrolidone (NMP) and also formic acid (0.02 g/l) (Japan). Elemental analysis of $\mathrm{C}, \mathrm{H}, \mathrm{N}$, and $\mathrm{S}$ was done by Costech instrument (ECS 4010) (USA). The cyclic voltammetry tests were done with $3 \%$ carbon paste $(0.006 \mathrm{~g}$ nanocomposite, $0.194 \mathrm{~g}$ graphite, 2 drops of paraffin) $0.1 \mathrm{M} \mathrm{HCl}, 100 \mathrm{mV} / \mathrm{s}$ scan rate and $0.2 \mathrm{~cm}^{2}$ electrode area relative to the $\mathrm{Ag} / \mathrm{AgCl}$ cell as a reference electrode. Thermogravimetric analysis (TGA) was carried out with the TGA1 Mettler Toledo
(Switzerland) analyzer at $10{ }^{\circ} \mathrm{C} / \mathrm{min}$ under $\mathrm{O}_{2}$ $\left(30 \mathrm{~cm}^{3} / \mathrm{min}\right)$ in a temperature range of $30-800^{\circ} \mathrm{C}$. $\mathrm{X}$-ray powder diffraction patterns were recorded by an X-ray diffractometer (GBC MMA instrument, Australia) with Be-filtered $\mathrm{CuK} \alpha(0.15418 \mathrm{~nm})$ operating at $35.4 \mathrm{kV}$ and $28 \mathrm{~mA}$. The $2 \theta$ scanning range was set between 10 and $90^{\circ}$ at a scan rate of $0.05^{\circ} \mathrm{s}$. The conductivity of the products was determined as tablets (bulk no film) by using a four-probe technique (Iran, Zahedan). Field Emission scanning electron microscopy (FESEM) pictures were performed on Cambridge Instrument S-360 SEM (England). Transmission electron microscope (TEM) was performed on a Philips CM-10 (Netherlands) at $100 \mathrm{kV}$.

\subsection{Synthesis of initiators (PAAB and DAAB)} $p$-Aminoazobenzene (PAAB) was synthesized using the method previously reported [31-33] and the orange solid was recrystallized from carbon tetrachloride. The yield and melting point were $71 \%$ and 124-126 ${ }^{\circ} \mathrm{C}$, respectively. Also, diazoaminobenzene (DAAB) was synthesized using the method reported in reference [34] and recrystallized in $n$-hexane. The yield and melting point were $93 \%$ and $94-96{ }^{\circ} \mathrm{C}$, respectively.

The structure of the initiators is shown in Figure 1. Their synthesis and purification were completely confirmed by color, m.p., FT-IR, ${ }^{1} \mathrm{H}-\mathrm{NMR}$ (proton nuclear magnetic resonance) and ${ }^{13} \mathrm{C}-\mathrm{NMR}\left({ }^{13} \mathrm{C}\right.$ nuclear magnetic resonance) spectroscopy techniques. Furthermore, the companies selling (Sigma-Aldrich and Merck) confirm the composition and structure of the compounds.

\subsection{Synthesis of polyaniline 1 (PANI-DAAB)}

The synthesis of PANI-DAAB was done by the following the rapid mixing polymerization procedure already explained in $[16,18,28,35] .3 .2 \mathrm{mmol}$ $(0.5 \mathrm{ml})$ of aniline is dissolved in $3.2 \mathrm{ml}$ of $\mathrm{HCl}$ $(1 \mathrm{M})$ and $0.064 \mathrm{mmol}(0.0126 \mathrm{~g}, 2 \%$ molar $)$ of
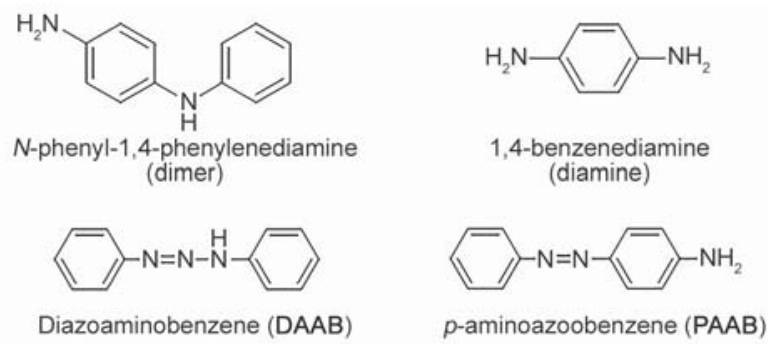

Figure 1. The chemical structure of PAAB and DAAB initiators and some others, used in the literature. 
DAAB is dissolved in a minimal amount of methanol and then added to the monomer solution at room temperature. Ammonium peroxydisulfate (APS) $(0.8 \mathrm{mmol}, 0.18 \mathrm{~g}$, and the ratio of monomer to oxidant equal to 0.25 ) is dissolved in $3.2 \mathrm{ml}$ of $1 \mathrm{M} \mathrm{HCl}$ in another beaker and added to the mixture of monomer and initiator. After that, the mixture of the reaction was shaken rapidly for 15 seconds and kept at room temperature without stirring for $12 \mathrm{~h}$. During this time, the solution color was changed from yellow to dark green. The dark green powder was collected via filtration and washed with $1 \mathrm{M} \mathrm{HCl}$ three times and then dried at room temperature for $12 \mathrm{~h}$ and in the oven at $50^{\circ} \mathrm{C}$ for $1 \mathrm{~h}$. The yield was $69.0 \%$.

\subsection{Synthesis of polyaniline 2 (PANI-PAAB)}

PANI-PAAB was synthesized using the method described in section 2.4, with the difference that the PAAB was used as the initiator in this synthesis. The green powder of PANI-PAAB was obtained with a yield of $66.0 \%$.

\section{Results and discussion}

\subsection{FT-IR spectra}

Based on Figure 3a, the FT-IR spectra of both samples are very similar. The same results were reported previously for PANI with the following main bands [36-41], respectively in PANI-DAAB and PANIPAAB spectra: 1581 and $1557 \mathrm{~cm}^{-1}(v \mathrm{C}=\mathrm{C}$ of the quinoid rings), 1479 and $1478 \mathrm{~cm}^{-1}(v \mathrm{C}=\mathrm{C}$ of the benzenoid rings), 1300 and $1297 \mathrm{~cm}^{-1}(v \mathrm{C}-\mathrm{N}$ radical cation), 1243 and $1248 \mathrm{~cm}^{-1}(v \mathrm{C}-\mathrm{N}$ benzene diamine units), and 1138 and $1122 \mathrm{~cm}^{-1}(\mathrm{C}-\mathrm{H}$ bending of the quinoid rings). In both spectra, a single broad band at about $3400 \mathrm{~cm}^{-1}$ corresponds to the stretching of the $\mathrm{N}-\mathrm{H}$ bond. At the wavenumbers higher than $2000 \mathrm{~cm}^{-1}$, the broad absorption band $\left(\sim 2350 \mathrm{~cm}^{-1}\right)$ in both spectra is typical of the conducting form of the polymers. The stretching of $\mathrm{S}-\mathrm{O}$ and the bending vibration of $\mathrm{O}-\mathrm{S}-\mathrm{O}$ in $\mathrm{NH}_{4} \mathrm{SO}_{4}-$ appears at 801 and $799 \mathrm{~cm}^{-1}$, and at 584 and $586 \mathrm{~cm}^{-1}$, respectively. $[37,38,42]$. The bonds at 859 and $861 \mathrm{~cm}^{-1}$ are attributed to 1,4-disubstituted rings in PANI-DAAB and PANI-PAAB polymers chains, respectively [42]. The peak of $\mathrm{N}=\mathrm{N}$ bond has not been seen in both spectra (this courier should appear in the area $\sim 1450 \mathrm{~cm}^{-1}$ ), probably because the initiators are in the center of the polymer network and the peak of $\mathrm{N}=\mathrm{N}$ bond do not have enough intensity to be seen.

\subsection{UV-vis spectroscopy}

The UV-vis spectra of polymers were obtained in two different solvents of NMP and formic acid, Figures $3 b$. Based on Figure $3 b / \alpha$ (in NMP), the peaks around $330 \mathrm{~nm}$ are assigned to $\pi \rightarrow \pi^{*}$ transition of the benzenoid ring and the peaks at $620 \mathrm{~nm}$ are assigned to the $n \rightarrow \pi *$ transition of the benzenoid ring to quinoid ring or exciton [35, 43-45]. For PANIDAAB, the absorption peak at $410 \mathrm{~nm}$ was indicated the presence of phenazine units (Figure 2) [43, 44] and polaron structure of the polymer [45-47]. The strong absorbance of this peak is due to the conjugation of formed phenazine unit with $\mathrm{N}=\mathrm{N}$ bond of diazoaminobenzene as an initiator.

Figure $3 b / \beta$ shows the spectra of the samples in formic acid. In both spectra, the first peaks (at 280 and $290 \mathrm{~nm}$ ) and the second peaks (at 320 and $340 \mathrm{~nm}$ ) are related to $\pi \rightarrow \pi^{*}$ transition of quinoid and benzenoid rings, respectively. The broad band over $795 \mathrm{~nm}$ is seen for samples in formic acid and is a characteristic of the polaron form. Formic acid acts as the secondary dopant and it makes the formation of polarons and bipolarons due to the full doping process $[35,47]$. As can be seen, the peaks at $795 \mathrm{~nm}$ correspond to $\pi \rightarrow$ polaron transition of located polarons and the peaks at 1080 and $1035 \mathrm{~nm}$ represent the delocated polaron [35, 45-50]. Also, PANI-DAAB in formic acid shows a strong peak at $510 \mathrm{~nm}$ corresponding to the phenazine unit which is shifted to a higher wavelength than the peak at $410 \mathrm{~nm}$ in NMP. This is due to protonation in the presence of formic acid and increased conjugation. The absorption intensity of this peak has increased in relation to the intensity of the same peak in Figure $3 b / \alpha$, due to phenazine unit coupling with the $\mathrm{N}=\mathrm{N}$ bond (Figure 2). As was seen in Section 3.1, the FT-IR spectra of the polymers were the same because their spectra are recorded in the solid state. But, the

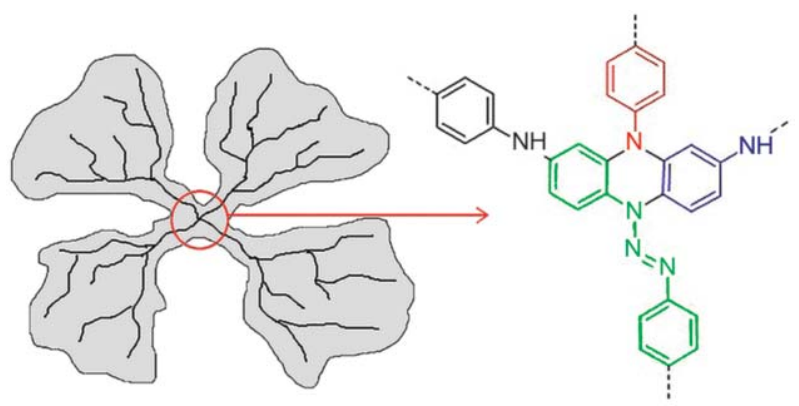

Figure 2. Proposed primary center in the initiation step of PANI-DAAB polymerization. The green segment presents DAAB as an initiator. 
UV-vis spectra of the polymers are different because they were dissolved in a solvent and as a result, the solvent type and the interactions between polymer chains and the solvent molecules have caused these differences [51].

\subsection{Elemental analysis (CHNS)}

The experimental and theroritical CHNS analysis results for the polymers were shown in Table 1. Different formulas were considered for both polymers and the percentages of each element were calculated, and eventually, we got the following formulas that have the best matching with the CHNS results.

The calculated data for PANI-DAAB for $\left(\mathrm{C}_{6} \mathrm{H}_{5} \mathrm{~N}\right)_{11} \cdot\left(\mathrm{NH}_{4} \mathrm{SO}_{4}\right)+4 \mathrm{Cl}$ and also for PANI-PAAB for $\left(\mathrm{C}_{6} \mathrm{H}_{5} \mathrm{~N}\right)_{8} \cdot\left(\mathrm{NH}_{4} \mathrm{SO}_{4}\right)_{3}+\mathrm{Cl}$ were listed in Table 1. Then, elemental analysis data is confirmed the proposed formula for both polymers.

The missing portion (23.29 and $27.49 \%$ for PANIDAAB and PANI-PAAB, respectively) from the total CHNS analysis have been assumed to be $\mathrm{HCl}$ molecules and the amounts of oxygen in the water molecules and $\mathrm{NH}_{4} \mathrm{SO}_{4}^{-}$ions. Therefore, the CHNS results confirmed clearly emeraldine structure in both PANI-DAAB and PANI-PAAB.

\subsection{Conductivity}

The electrical conductivity of the PANI-DAAB and PANI-PAAB were measured by the four-probe technique at room temperature. The pellets were prepared by subjecting the polymer powder to a pressure of $30 \mathrm{MPa}$. The obtained values are an average of at least four measurements. The PANI-DAAB and PANI-PAAB have a conductivity of $3.4 \cdot 10^{-3}$ and $9.1 \cdot 10^{-3} \mathrm{~S} / \mathrm{cm}$, respectively that set in the region of semiconductive polymers [52, 53]. PANI-PAAB with nanosheet morphology has the most conductivity due to its morphology and so longer conjugated flat system.

\subsection{Cyclic voltammetry}

Cyclic voltammetry experiments of the synthesized polymers were done with $3 \%$ carbon paste $(0.006 \mathrm{~g}$ of polymer, $0.194 \mathrm{~g}$ graphite and 3 drops of paraffin were mixed in a mortar and pestle and then filled in a glass tube with inner diameter $2 \mathrm{~mm}$ and a copper wire for the connection) in $0.1 \mathrm{M} \mathrm{HCl}$ as supporting electrolyte, $100 \mathrm{mV} / \mathrm{s} \mathrm{scan}$ rate and $0.0314 \mathrm{~cm}^{2}$ electrode area. The $\mathrm{Ag} / \mathrm{AgCl}$ and platinum wire electrodes were used as reference and counter electrodes, respectively. The results for modified electrodes were shown in Figure 3. The voltammograms of both polymers show two processes of well-defined reversible redox of polyaniline, confirming that the polymers show a good electroactivity. Furthermore, such redox peaks confirm the formation of the polymers $[35,45,48,54]$. In the same condition, the graphite paste electrode without modifier did not show any redox peak (That is not shown here). These results are indicating that the redox peaks in modified

Table 1. Elements ratio consisted of PANI-DAAB and PANI-PAAB.

\begin{tabular}{|c|c|c|c|c|c|c|c|c|}
\hline \multicolumn{2}{|l|}{ Sample } & $\mathrm{C}$ & H & $\mathbf{N}$ & $\mathbf{S}$ & $\mathbf{O}^{\mathrm{a}}$ & $\mathbf{C} / \mathbf{N}$ & $\mathbf{N} / \mathbf{S}$ \\
\hline \multirow{3}{*}{ PANI-DAAB } & {$[\% \mathrm{~W}]$} & 58.70 & 3.03 & 12.68 & 2.30 & 5.08 & \multirow{3}{*}{5.40} & \multirow{3}{*}{12.62} \\
\hline & [mole] & 4.88 & 3.03 & 0.90 & 0.07 & 0.32 & & \\
\hline & [mole ratio] & 68.16 & 42.67 & 12.62 & 1.00 & 4.47 & & \\
\hline$\left(\mathrm{C}_{6} \mathrm{H}_{5} \mathrm{~N}\right)_{11} \cdot\left(\mathrm{NH}_{4} \mathrm{SO}_{4}\right)+4 \mathrm{Cl}^{\mathrm{b}}$ & {$[\% \mathrm{~W}]$} & 63.00 & 2.08 & 13.36 & 2.54 & 5.09 & & \\
\hline \multirow{3}{*}{ PANI-PAAB } & {$[\% \mathrm{~W}]$} & 46.42 & 4.60 & 13.22 & 8.27 & 19.29 & \multirow{3}{*}{3.48} & \multirow{3}{*}{3.65} \\
\hline & [mole] & 3.28 & 4.60 & 0.94 & 0.25 & 1.20 & & \\
\hline & [mole ratio] & 12.72 & 18.40 & 3.65 & 1.00 & 4.80 & & \\
\hline$\left(\mathrm{C}_{6} \mathrm{H}_{5} \mathrm{~N}\right)_{8} \cdot\left(\mathrm{NH}_{4} \mathrm{SO}_{4}\right)_{3}+\mathrm{Cl}^{\mathrm{c}}$ & {$[\% \mathrm{~W}]$} & 52.10 & 4.70 & 13.93 & 8.68 & 17.36 & & \\
\hline
\end{tabular}

${ }^{\mathrm{a}}$ Calculated based on $\% \mathrm{~S}$ and for $\% \mathrm{O}$ in $\mathrm{SO}_{4}^{2-}$, ${ }^{b}$ Proposed formula for PANI-DAAB, ${ }^{c}$ Proposed formula for PANI-PAAB.

Table 2. The reversible redox peaks of PANI-DAAB and PANI-PAAB.

\begin{tabular}{|l|c|c|c|c|}
\hline \multirow{2}{*}{ Sample } & \multicolumn{2}{|c|}{$\begin{array}{c}\text { Oxidation peaks } \\
\text { [V] }\end{array}$} & $\begin{array}{c}\text { Reduction peaks } \\
{[V]}\end{array}$ \\
\cline { 2 - 5 } & $\begin{array}{c}\text { Leucoemeraldine to } \\
\text { emeraldine }\end{array}$ & $\begin{array}{c}\text { Emeraldine to } \\
\text { Pernigraniline }\end{array}$ & $\begin{array}{c}\text { Pernigraniline to } \\
\text { emeraldine } \\
\text { Leucoemeraldine }\end{array}$ \\
\hline PANI-DAAB & 0.300 & 0.800 & 0.500 & 0.030 \\
\hline PANI-PAAB & 0.065 & 0.480 & 0.165 & -0.206 \\
\hline
\end{tabular}


graphite paste electrode are coming from PANIDAAB and PANI-PAAB. The details for redox peak
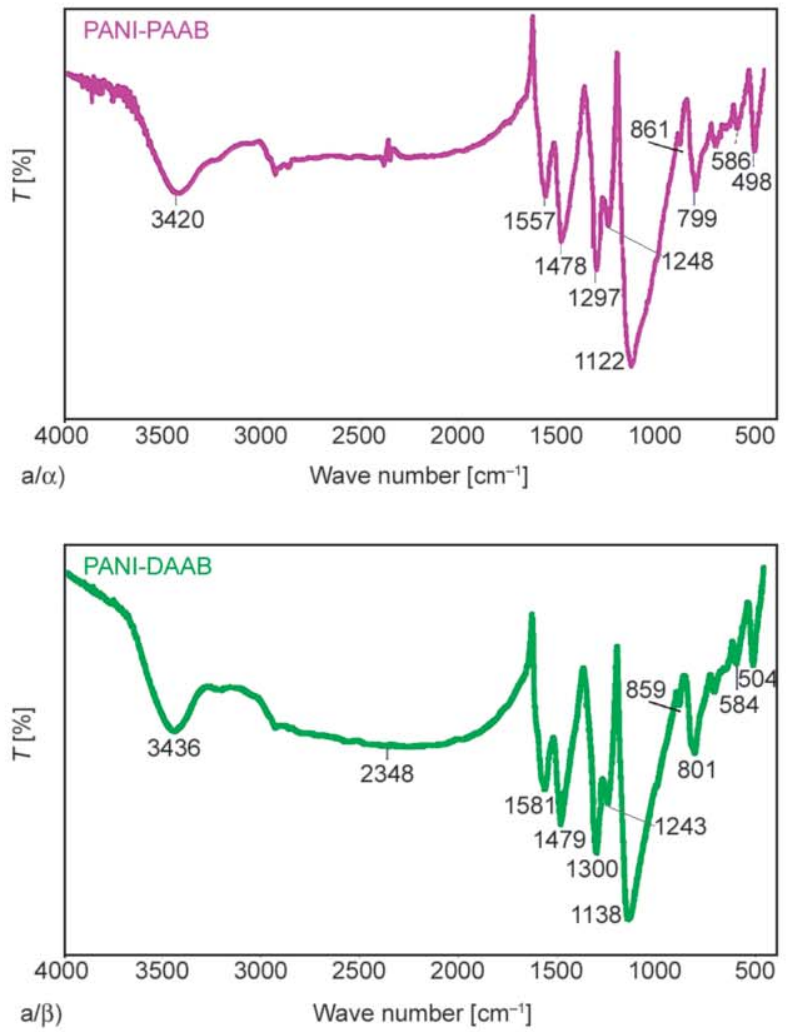

potentials for the graphite paste electrode with PANI-DAAB and PANI-PAAB are summarized in
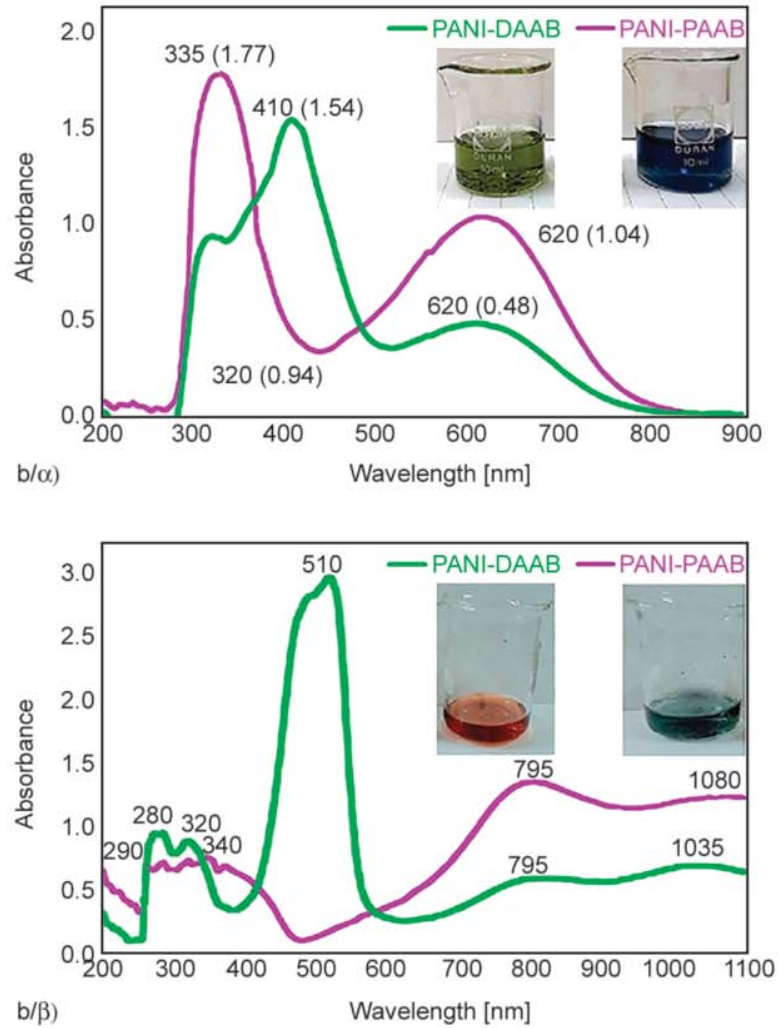
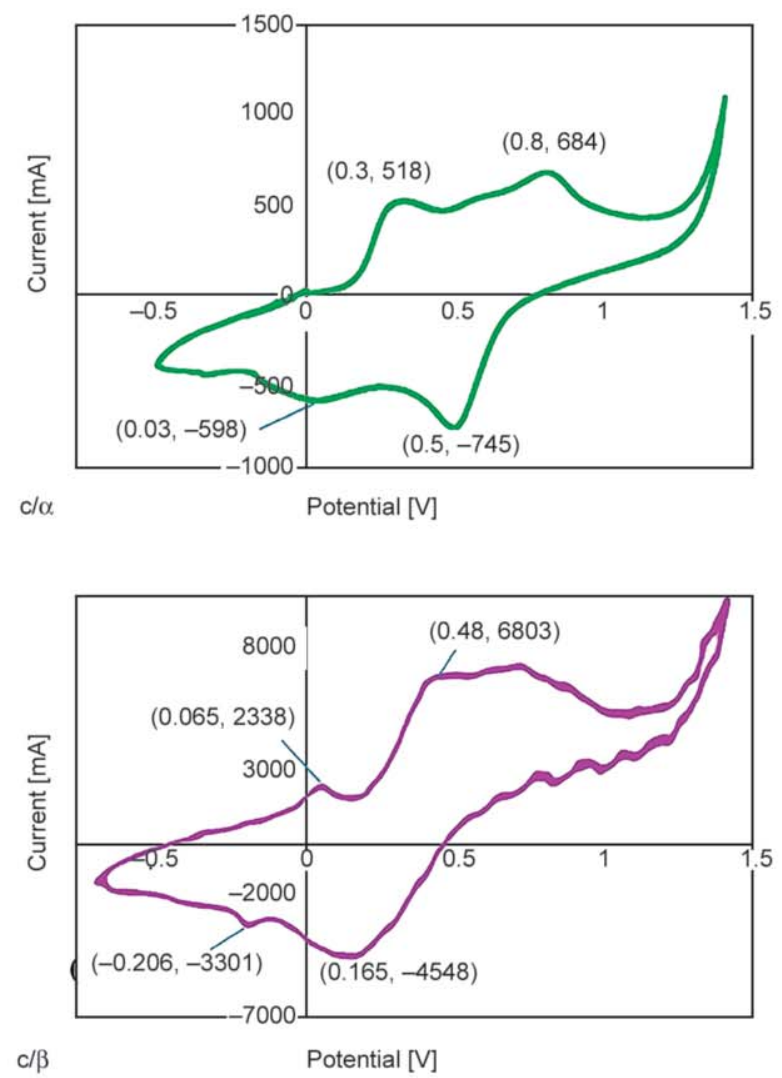

Figure 3. a) FT-IR spectra of $\alpha$ ) PANI-DAAB and $\beta$ ) PANI-PAAB, b) UV-vis spectra of PANI-DAAB and PANI-PAAB $\alpha)$ in NMP $(0.02 \mathrm{~g} / \mathrm{l})$ and $\beta)$ in formic acid $(0.02 \mathrm{~g} / \mathrm{l})$, c) cyclic voltammograms of $\alpha)$ PANI-DAAB and $\beta)$ PANIPAAB. 
Table 2. Based on Figures $3 \mathrm{c} / \alpha$ and $3 \mathrm{c} / \beta$, the redox potentials for PANI-PAAB are lower than PANIDAAB and it is an indication that PANI-PAAB with nanosheet morphology has so longer conjugated flat system. This is in agreement with conductivity.

\subsection{Thermal properties}

TGA curves of PANI-DAAB and PANI-PAAB are shown in Figure 4a. The TGA curves of both polymers are exactly similar under $\mathrm{O}_{2}$ and at a heating rate of $10^{\circ} \mathrm{C} / \mathrm{min}$ up to $800^{\circ} \mathrm{C}$. The corresponding data of $T_{10 \%}$, char yields (C.Y.), and the limiting oxygen indexes (LOI) which are obtained by Van Krevelen and Hoftyzer equation $(\mathrm{DOI}=17.5+0.4 \mathrm{C} . \mathrm{Y}$ [55]) are listed in Table 3. Substantially, self-extinguishable polymers have an LOI more than $26 \%$, as a result, PANI-DAAB and PANI-PAAB are not included in this category $[55,56]$. According to both curves, the first weight loss (about $11 \%$ ) can be related to water or $\mathrm{HCl}$ withdrawal below $150^{\circ} \mathrm{C}$. The second weight loss about $4 \%$ between $150^{\circ} \mathrm{C}$ and $280^{\circ} \mathrm{C}$ has indicated the loss of removing $\mathrm{NH}_{3}$ molecules due to the presence of $\left[\mathrm{NH}_{4} \mathrm{SO}_{4}\right]^{-}$dopant molecules alongside the polymer chains. The third step between $280-650^{\circ} \mathrm{C}$ is assigned to the thermal structural decomposition of the polymer and removal of $\mathrm{N}_{2}, \mathrm{NO}_{2}$ and $\mathrm{CO}_{2}$ groups and the removal of $\mathrm{SO}_{3}$ group from the polymer due to presence of $\left[\mathrm{NH}_{4} \mathrm{SO}_{4}\right]^{-}$species as dopant anion (about $84 \%$ ) (5.75 and $20.67 \%$ for $\mathrm{SO}_{3}$ amount for PANI-DAAB and PANI-PAAB are calculated according to the 2.3 and $8.27 \%$ of the $\mathrm{S}$ amount observed in their CHNS analysis) [56] that it is completely in good agreement with $\% \mathrm{~S}$ and $\%$ sum of $\mathrm{C}, \mathrm{N}, \mathrm{H}, \mathrm{S}$ and $\mathrm{O}=81.79 \%$

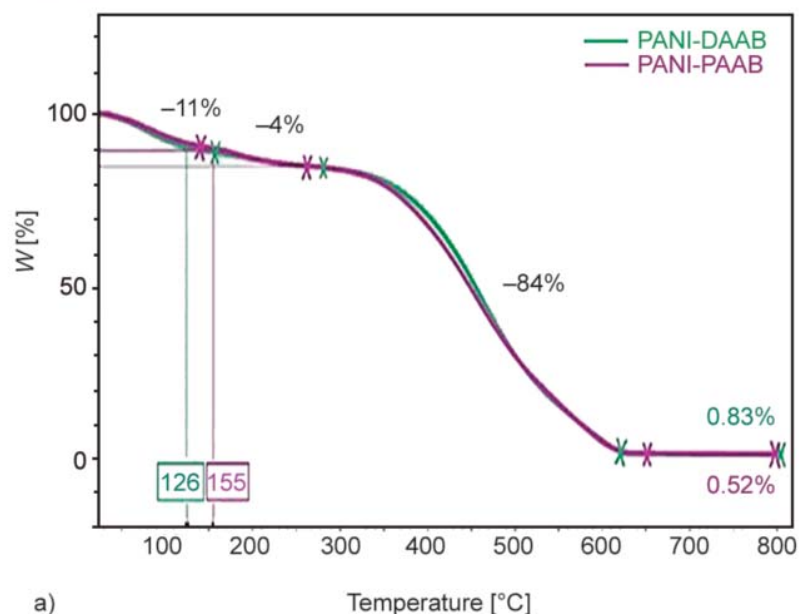

Table 3. Thermal properties of PANI-DAAB and PANIPAAB.

\begin{tabular}{|c|c|c|c|}
\hline Sample & $\begin{array}{l}\text { C.Y. } \\
{[\%]}\end{array}$ & $\begin{array}{l}\boldsymbol{T}_{\mathbf{1 0} \%} \\
{\left[{ }^{\circ} \mathbf{C}\right]}\end{array}$ & LOI \\
\hline PANI-DAAB & 0.83 & 126 & 17.83 \\
\hline PANI-PAAB & 0.52 & 155 & 17.70 \\
\hline
\end{tabular}

for PANI-DAAB and $91.8 \%$ for PANI-PAAB from CHNS results.

\subsection{Analysis of X-ray diffraction (XRD)}

The nature of the polymers was examined by X-ray diffraction (XRD) measurement and the resulted patterns are shown in Figure 4b. In both patterns, the characteristic amorphous peaks centered at $2 \theta=20$ and $44^{\circ}$ and the sharp peaks at $2 \theta=14$ and $25^{\circ}$ are visible. According to these patterns, both polymers are semi-crystalline in nature [55-58].

\subsection{Morphology analysis}

The FESEM and TEM images of the products are shown in Figures 5a and 5b, respectively. According to FESEM images (Figure $5 \mathrm{a} / \alpha$ ), the short string-like nanostructure with an average diameter of $58 \mathrm{~nm}$ is shown for PANI-DAAB. The TEM images of this polymer (Figure $5 \mathrm{~b} / \alpha$ ) show the flower-like dendrimer nanostructure with an apparent center. This morphology is essentially the result of the initiator effect and is due to initiation reactions of the initiator with the monomers and the primary formed structure at the onset of the reaction. A few papers about the fractal structure of polyaniline have been reported [19-21], but the dendrimer structure of polyaniline was not obtained with an apparent center, yet. The proposed primary center with four branches of this

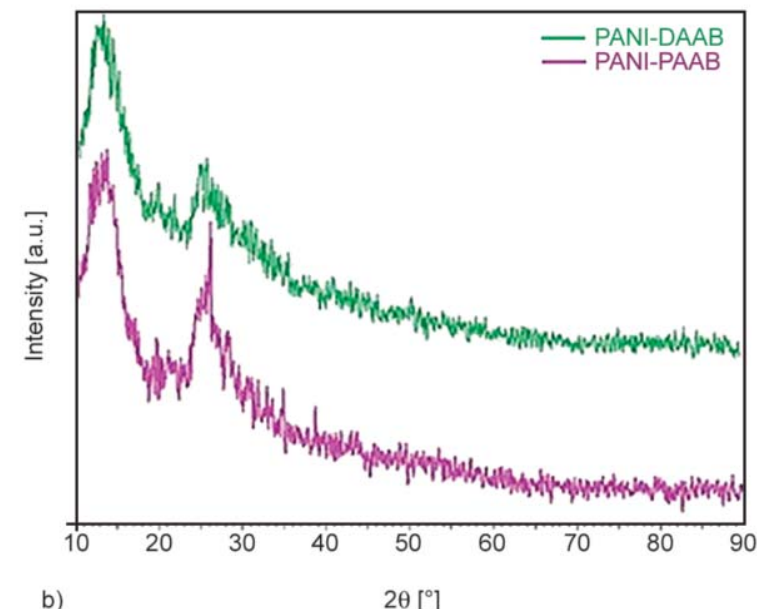

b)

Figure 4. a) TGA curves of PANI-DAAB and PANI-PAAB under $\mathrm{O}_{2}$ at a heating rate of $10^{\circ} \mathrm{C} / \mathrm{min}$, b) X-ray diffraction patterns of PANI-DAAB and PANI-PAAB. 
morphology based on the initiator structure is shown in Figure 2. As can be seen in Figure 2, DAAB initiator was drawn in green color. It was reacted with three aniline monomers and a center with four sites was formed to grow the polymer chains.

The FESEM images of PANI-PAAB indicate the nanosheet morphology with an average thickness of $51 \mathrm{~nm}$ and the average length about $2 \mu \mathrm{m}$ along with shapeless nanoparticles with the average size of $50 \mathrm{~nm}$. As can be seen in the Figure $5 \mathrm{a} / \beta$, these nanosheets are flexible. Also, the TEM images in Figure $5 \mathrm{~b} / \beta$ show small nanosheets that are interspersed and confirm the morphology seen in FESEM images. The size of the sheets in the TEM images is lower than in the FESEM micrographs, which is probably due to the fact that the sheets were broken in the preparation steps of TEM (dispersion in ethanol by ultrasonic bath) as reported before [59]. The mechanism of the nanosheet formation was reported before $[23-30,59]$ and also applies to the polyaniline nanosheet formation in this paper. Actually, when sulfuric acid is formed at the beginning of the reaction, the $\mathrm{pH}$ of the solution is reduced and the phenazine units can be formed and precipitate in solution as plate-like crystals. Then, they grow chains of oligomers by linking to another monomer, simultaneously. They precipitate as flat nanosheet structures, due to possible $\pi-\pi$ stacking interactions between the layers. The formation of cross-linked
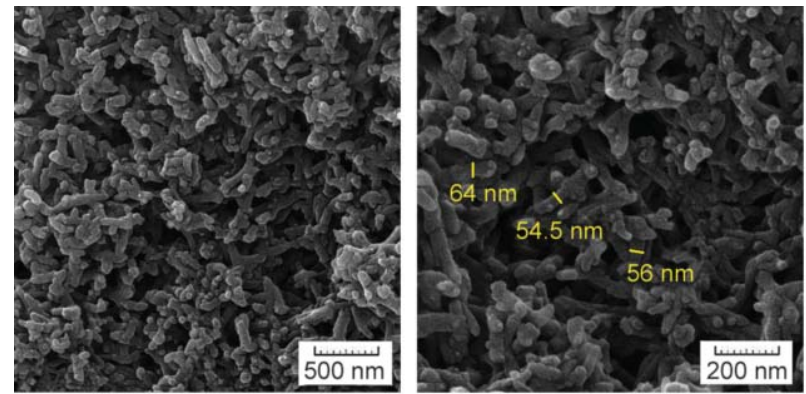

$\mathrm{a} / \alpha)$
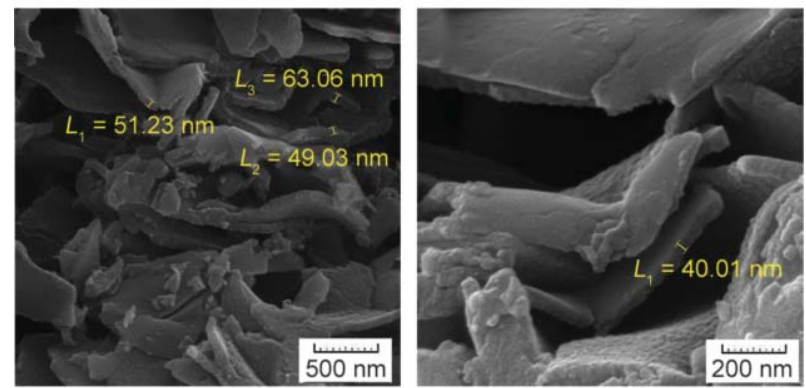

$a / \beta)$ polymer structure occurs through the imine nitrogen of a chain with a quinoid ring of another chain [25$30,59]$.

Indeed, species of the phenazine type act as initiation centers. The resulting polymer is thus expected to have a phenazine head segment and a tail of paralinked aniline constitutional units. When the $\mathrm{pH}$ becomes sufficiently low, chain propagation from these initiation centers becomes feasible from para position results in the formation of high-molecular-weight chains. The because of low number of initiation centers their intensity is not significant to detect in FTIR, UV-vis and NMR spectroscopy. Thus, phenazine units are not observed in FT-IR and UV-vis in opposition to phenazine units in PANI-DAAB that they are repeated in each generation of dendritic form. As a result, this is evidence for dendrimer morphology. It was observed that in the same synthetic condition just with the initiator changing, the different morphologies were obtained. These observations show clearly the effect of the initiator structure on the morphology.

Control experiment without initiator was carried out and its FT-IR, UV-vis, conductivity and morphology were compared with PANI-PAAB and PANI-DAAB. Conductivity of PANI synthesized without initiatorwas measured as $2.2 \cdot 10^{-3} \mathrm{~S} / \mathrm{cm}$, which is less than the conductivities of PANI-PAAB and PANI-DAAB. It can be related to the morphology of the polymers.
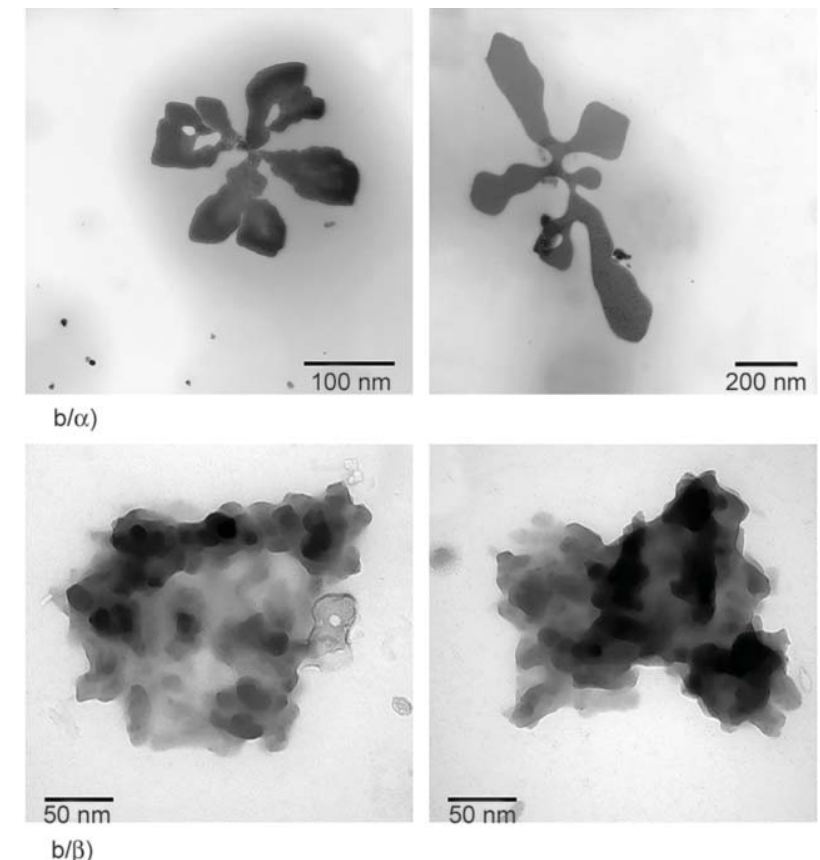

$\mathrm{b} / \beta$ )

Figure 5. a) FESEM images of $\alpha$ ) PANI-DAAB and $\beta$ ) PANI-PAAB, b) TEM images of $\alpha$ ) PANI-DAAB and $\beta$ ) PANIPAAB. 
PANI-PAAB with nanosheet morphology has the most conductivity due to its morphology and so longer conjugated flat system. The FESEM images of the PANI proved (they have not been shown) polyaniline synthesized in the absence of initiator has a different morphology (irregular and agglomerate). So, it can be concluded that the initiators played a major role in the formation of observed morphologies. The FT-IR and UV-vis of PANI recorded (they have not been shown here)) were the same to PANIDAAB and PANI-PAAB.

\section{Conclusions}

In summary, the synthesis of polyaniline using two new initiators (DAAB and PAAB) was done successfully. The electrical conductivity, crystallinity, optical, thermal and electrochemical properties of the polymers were investigated. Also, the effect of the initiators on the properties and the morphology of the polymers was studied. The dendrimer morphology obtained for polyaniline with an apparent center was reported for the first time. Actually, the polyaniline dendrimer was formed in the present of DAAB as an initiator. Then, the mechanism of the initiation step and the structure of the dendrimer center were presented. Also, the nanosheet morphology was observed for polyaniline synthesized at the presence of PAAB as an initiator. Indeed, these observations show clearly the effect of the initiator structure on the morphology of polyaniline that certainly creates new applications for it. The more studies on these initiators are in progress.

\section{Acknowledgements}

The authors acknowledge from the National Nanotechnology Initiative funded by the Iranian Government and the Graduate Council of University of Sistan and Baluchestan because of the financial support.

\section{References}

[1] Chandrasekhar P.: Conducting polymers, fundamentals and applications: A practical approach. Springer, Boston (1999). https://doi.org/10.1007/978-1-4615-5245-1

[2] Wallace G., Teasdale P. R., Spinks G. M., KaneMaguire L. A. P.: Conductive electroactive polymers. Intelligent polymer systems. Taylor and Francis, Boca Raton (2009).

https://doi.org/10.1201/9781420067156
[3] Eftekhari A.: Nanostructured conductive polymers. Wiley, Cincinnati (2011). https://doi.org/10.1002/9780470661338

[4] Joseph N., Varghese J., Sebastian M. T.: In situ polymerized polyaniline nanofiber-based functional cotton and nylon fabrics as millimeter-wave absorbers. Polymer Journal, 49, 391-399 (2017).

https://doi.org/10.1038/pj.2016.121

[5] Araujo P. L. B., Santos R. F. S., Araujo E. S.: Polyaniline nanofibers as a new gamma radiation stabilizer agent for PMMA. Express Polymer Letters, 1, 385-390 (2007).

https://doi.org/10.3144/expresspolymlett.2007.54

[6] Solonaru A. M., Grigoras M.: Water-soluble polyaniline/graphene composites as materials for energy storage applications. Express Polymer Letters, 11, 127-139 (2017).

https://doi.org/10.3144/expresspolymlett.2017.14

[7] Maiti S., Khatua B. B.: Polyaniline integrated carbon nanohorn: A superior electrode materials for advanced energy storage. Express Polymer Letters, 8, 895-907 (2014).

https://doi.org/10.3144/expresspolymlett.2014.91

[8] Chiou N-R., Lu C., Guan J., Lee L. J., Epstein A. J.: Growth and alignment of polyaniline nanofibres with superhydrophobic, superhydrophilic and other properties. Nature Nanotechnology, 2, 354-357 (2007). https://doi.org/10.1038/nnano.2007.147

[9] Baker C. O., Shedd B., Innis P. C., Whitten P. G., Spinks G. M., Wallace G. G., Kaner R. B.: Monolithic actuators from flash-welded polyaniline nanofibers. Advanced Materials, 20, 155-158 (2008). https://doi.org/10.1002/adma.200602864

[10] Virji S., Huang J., Kaner R. B., Weiller B. H.: Polyaniline nanofiber gas sensors: Examination of response mechanisms. Nano Letters, 4, 491-496 (2004). https://doi.org/10.1021/n1035122e

[11] Janata J., Josowicz M.: Conducting polymers in electronic chemical sensors. Nature Materials, 2, 19-24 (2003). https://doi.org/10.1038/nmat768

[12] Sukeerthi S., Contractor A. Q.: Molecular sensors and sensor arrays based on polyaniline microtubules. Analytical Chemistry, 71, 2231-2236 (1999). https://doi.org/10.1021/ac9810213

[13] Agrawalla R. K., Meriga V., Paul R., Chakraborty A. K. Mitra A. K.: Solvothermal synthesis of a polyaniline nanocomposite - A prospective biosensor electrode material. Express Polymer Letters, 10, 780-787 (2016). https://doi.org/10.3144/expresspolymlett.2016.72

[14] Tiwari A., Shukla S. K.: Chitosan-g-polyaniline: A creatine amidinohydrolase immobilization matrix for creatine biosensor. Express Polymer Letters, 3, 553-559 (2009). https://doi.org/10.3144/expresspolymlett.2009.69 
[15] Wu C-G., Bein T.: Polyaniline wires in oxidant-containing mesoporous channel hosts. Chemistry of Materials, 6, 1109-1112 (1994). https://doi.org/10.1021/cm00044a008

[16] Tran H. D., Norris I., D’Arcy J. M., Tsang H., Wang Y., Mattes B. R., Kaner R. B.: Substituted polyaniline nanofibers produced via rapid initiated polymerization. Macromolecules, 41, 7405-7410 (2008).

https://doi.org/10.1021/ma800122d

[17] Zujovic Z. D., Wang Y., Bowmaker G. A., Kaner R. B.: Structure of ultralong polyaniline nanofibers using initiators. Macromolecules, 44, 2735-2742 (2011). https://doi.org/10.1021/ma102772t

[18] Movahedifar F., Modarresi-Alam A. R.: The effect of initiators and oxidants on the morphology of poly $[( \pm)$ 2-(sec-butyl) aniline] a chiral bulky substituted polyaniline derivative. Polymers for Advanced Technologies, 27, 131-139 (2016). https://doi.org/10.1002/pat.3614

[19] Menon R., Mukherjee A. K.: Polyaniline fractal nanocomposites. in 'Encyclopedia of nanoscience and nanotechnology' (ed.: Nalwa H. S.) American Scientific Publishers, Los Angeles, Vol 8, 715-729 (2004).

[20] Du X-S., Zhou C-F., Wang G-T., Mai Y-W.: Novel solid-state and template-free synthesis of branched polyaniline nanofibers. Chemistry of Materials, 20, 38063808 (2008).

https://doi.org/10.1021/cm800689b

[21] Wu Q., Wu L., Qi Z., Wang F.: The fractal structures in highly sulfonated polyaniline. Synthetic Metals, 105, 13-16 (1999).

https://doi.org/10.1016/S0379-6779(99)00082-X

[22] Trchová M., Šeděnková I., Konyushenko E. N., Stejskal J., Holler P., Ćirić-Marjanović G.: Evolution of polyaniline nanotubes: The oxidation of aniline in water. The Journal of Physical Chemistry B, 110, 9461-9468 (2006). https://doi.org/10.1021/jp057528g

[23] Zhou C., Han J., Song G., Guo R.: Polyaniline hierarchical structures synthesized in aqueous solution: Micromats of nanofibers. Macromolecules, 40, 7075-7078 (2007). https://doi.org/10.1021/ma071400a

[24] Song S-Y., Pan L-J., Li Y., Shi Y., Pu L., Zhang R., Zheng Y-D.: Self-assembly of polyaniline: Mechanism study. Chinese Journal of Chemical Physics, 21, 187 192 (2008).

https://doi.org/10.1088/1674-0068/21/02/187-192

[25] Konyushenko E. N., Stejskal J., Šeděnková I., Trchová M., Sapurina I., Cieslar M., Prokeš J.: Polyaniline nanotubes: Conditions of formation. Polymer International, 55, 31-39 (2006). https://doi.org/10.1002/pi.1899

[26] Zhang Y., Dou C., Wang W., Wang Q., Feng N.: Synthesis of uniform polyaniline nanosheets and nanotubes: Dependence of morphology on the $\mathrm{pH}$. Macromolecular Research, 24, 663-669 (2016).

https://doi.org/10.1007/s13233-016-4097-2
[27] Seo H-K., Ameen S., Akhtar M. S., Shin H. S.: Structural, morphological and sensing properties of layered polyaniline nanosheets towards hazardous phenol chemical. Talanta, 104, 219-227 (2013).

https://doi.org/10.1016/j.talanta.2012.10.089

[28] Tran H. D., D'Arcy J. M., Wang Y., Beltramo P. J., Strong V. A., Kaner R. B.: The oxidation of aniline to produce 'polyaniline': A process yielding many different nanoscale structures. Journal of Materials Chemistry, 21, 3534-3550 (2011). https://doi.org/10.1039/C0JM02699A

[29] Tran H. D., Li D., Kaner R. B.: One-dimensional conducting polymer nanostructures: Bulk synthesis and applications. Advanced Materials, 21, 1487-1499 (2009). https://doi.org/10.1002/adma.200802289

[30] Liu P., Qiu J., Wang X., Wu X.: Facile preparation of polyaniline nanosheets via chemical oxidative polymerization in saturated $\mathrm{NaCl}$ aqueous solution for supercapacitors. International Journal of Electrochemical Science, 7, 6134-6141 (2012).

[31] Kumar T. K., Janarthanan S., Pandi S., Raj M. V., Kanagalakshmi J., Anand D. P.: Synthesis, growth and characterization of 4-benzeneazoaniline single crystal. Journal of Minerals and Materials Characterization and Engineering, 9, 961-972 (2010). https://doi.org/10.4236/jmmce.2010.911069

[32] Hartman W. W., Dickey J. B.: Working with hazardous chemicals: Diazoaminobenzene. Organic Syntheses, 14, 24-26 (1934).

https://doi.org/10.15227/orgsyn.014.0024

[33] Kidd H. V.: Mechanism of the diazoaminobenzene conversion. The Journal of Organic Chemistry, 2, 198-208 (1937). https://doi.org/10.1021/jo01225a008

[34] Vogel A. I.: Textbook of practical organic chemistry including qualitative organic analysis. Longmans, London (2013).

[35] Modarresi-Alam A. R., Amirazizi H. A., Movahedifar F., Farrokhzadeh A., Asli G. R., Nahavandi H.: The first report of polymerization and characterization of aniline bearing chiral alkyl group on ring via covalent bond; poly $[( \pm)$-2-(sec-butyl)aniline]. Journal of Molecular Structure, 1083, 17-26 (2015).

https://doi.org/10.1016/j.molstruc.2014.11.003

[36] Sim B., Chae H. S., Choi H. J.: Fabrication of polyaniline coated iron oxide hybrid particles and their dual stimuli-response under electric and magnetic fields. Express Polymer Letters, 9, 736-743 (2015). https://doi.org/10.3144/expresspolymlett.2015.68

[37] Trchová M., Šeděnková I., Tobolková E., Stejskal J.: FTIR spectroscopic and conductivity study of the thermal degradation of polyaniline films. Polymer Degradation and Stability, 86, 179-185 (2004). https://doi.org/10.1016/j.polymdegradstab.2004.04.011

[38] Trchová M., Stejskal J.: Polyaniline: The infrared spectroscopy of conducting polymer nanotubes (IUPAC technical report). Pure and Applied Chemistry, 83, 18031817 (2011).

https://doi.org/10.1351/PAC-REP-10-02-01 
[39] Sariciftci N. S., Bartonek M., Kuzmany H., Neugebauer H., Neckel A.: Analysis of various doping mechanisms in polyaniline by optical, FTIR and Raman spectroscopy. Synthetic Metals, 29, 193-202 (1989). https://doi.org/10.1016/0379-6779(89)90296-8

[40] Louarn G., Lapkowski M., Quillard S., Pron A., Buisson J. P., Lefrant S.: Vibrational properties of polyanilineisotope effects. The Journal of Physical Chemistry, 100, 6998-7006 (1996).

https://doi.org/10.1021/jp953387e

[41] da Silva J. P., Temperini M. L., de Torresi S. C.: Secondary doping of polyaniline studied by resonance Raman spectroscopy. Electrochimica Acta, 44, 1887-1891 (1999).

https://doi.org/10.1016/S0013-4686(98)00330-2

[42] Yacovitch T. I., Wende T., Jiang L., Heine N., Meijer G., Neumark D. M., Asmis K. R.: Infrared spectroscopy of hydrated bisulfate anion clusters: $\mathrm{HSO}_{4}^{-}\left(\mathrm{H}_{2} \mathrm{O}\right)_{1-16}$. The Journal of Physical Chemistry Letters, 2, 2135-2140 (2011).

https://doi.org/10.1021/jz200917f

[43] Li X-G., Huang M-R., Duan W., Yang Y-L.: Novel multifunctional polymers from aromatic diamines by oxidative polymerizations. Chemical Reviews, 102, 2925 3030 (2002).

https://doi.org/10.1021/cr010423z

[44] Tang S-J., Wang A-T., Lin S-Y., Huang K-Y., Yang C-C., Yeh J-M., Chiu K-C.: Polymerization of aniline under various concentrations of APS and $\mathrm{HCl}$. Polymer Journal, 43, 667-680 (2011).

https://doi.org/10.1038/pj.2011.43

[45] Farrokhzadeh A., Modarresi-Alam A. R.: Complete doping in solid-state by silica-supported perchloric acid as dopant solid acid: Synthesis and characterization of the novel chiral composite of poly [( \pm )-2-(sec-butyl) aniline]. Journal of Solid State Chemistry, 237, 258 268 (2016).

https://doi.org/10.1016/j.jssc.2016.02.032

[46] Modarresi-Alam A. R., Zeraatkar V., Tabatabaei F. A., Bazrafkan M., Salmani Dastgerdi A., Malekmakan R.: A solid-state synthesis, mechanism, and characterization of high molecular weight poly(3-aminobenzenesulfonic acid) with $\mathrm{FeCl}_{3} \cdot 6 \mathrm{H}_{2} \mathrm{O}$ as a binary oxidant and dopant. Journal of Polymer Research, 26, 22/1-22/16 (2019).

https://doi.org/10.1007/s10965-018-1674-4

[47] MacDiarmid A. G., Epstein A. J.: The concept of secondary doping as applied to polyaniline. Synthetic Metals, 65, 103-116 (1994).

https://doi.org/10.1016/0379-6779(94)90171-6

[48] Modarresi-Alam A. R., Zafari S., Miandashti A. R.: A facile preparation method for synthesis of silica sulfuric acid/poly(o-methoxyaniline) core-shell nanocomposite. Polymers for Advanced Technologies, 26, 645-657 (2015). https://doi.org/10.1002/pat.3499
[49] Stejskal J., Sapurina I., Trchová M.: Polyaniline nanostructures and the role of aniline oligomers in their formation. Progress in Polymer Science, 35, 1420-1481 (2010).

https://doi.org/10.1016/j.progpolymsci.2010.07.006

[50] Leclerc M., Guay J., Dao L. H.: Synthesis and characterization of poly(alkylanilines). Macromolecules, 22, 649-653 (1989).

https://doi.org/10.1021/ma00192a024

[51] Tomšík E., Kohut O., Ivanko I., Pekárek M., Bieloshapka I., Dallas P.: Assembly and interaction of polyaniline chains: Impact on electro- and physical-chemical behavior. The Journal of Physical Chemistry C, 122, 80228030 (2018).

https://doi.org/10.1021/acs.jpcc.8b01948

[52] Qiang J., Yu Z., Wu H., Yun D.: Polyaniline nanofibers synthesized by rapid mixing polymerization. Synthetic Metals, 158, 544-547 (2008).

https://doi.org/10.1016/j.synthmet.2008.03.023

[53] Shen J., Sugimoto I., Matsumoto T., Horike S., Koshiba Y., Ishida K., Mori A., Nishino T.: Fabrication and characterization of elastomeric semiconductive thiophene polymers by peroxide crosslinking. Polymer Journal, 51, 257-263 (2019).

https://doi.org/10.1038/s41428-018-0137-4

[54] Stejskal J., Gilbert R. G.: Polyaniline. Preparation of a conducting polymer(IUPAC technical report). Pure and Applied Chemistry, 74, 857-867 (2002). https://doi.org/10.1351/pac200274050857

[55] van Krevelen W., Hoftyzer P. J.: Properties of polymers. Elsevier, Amsterdam (2008).

[56] Ghaemy M., Shabzendedar S., Taghavi M.: One-step synthesis of poly(triazole-ether-quinoxaline)s using click reaction: Preparation and properties of magnetic nanocomposites with modified $\mathrm{Fe}_{3} \mathrm{O}_{4}$ for metal ions removal. Journal of Polymer Research, 21, 464-480 (2014). https://doi.org/10.1007/s10965-014-0464-x

[57] Sanches E. A., Soares J. C., Mafud A. C., Fernandes E. G. R., Leite F. L., Mascarenhas Y. P.: Structural characterization of chloride salt of conducting polyaniline obtained by XRD, SAXD, SAXS and SEM. Journal of Molecular Structure, 1036, 121-126 (2013).

https://doi.org/10.1016/j.molstruc.2012.09.084

[58] Raghunathan A., Rangarajan G., Trivedi D. C.: 13C CPMAS NMR, XRD, d.c. and a.c. electrical conductivity of aromatic acids doped polyaniline. Synthetic Metals, 81, 39-47 (1996). https://doi.org/10.1016/0379-6779(96)80227-X

[59] Laslau C., Zujovic Z., Travas-Sejdic J.: Theories of polyaniline nanostructure self-assembly: Towards an expanded, comprehensive multi-layer theory (MLT). Progress in Polymer Science, 35, 1403-1419 (2010). https://doi.org/10.1016/j.progpolymsci.2010.08.002 